\title{
WorldSkills UK Training Managers: Midas Touch or Fool's Gold?
}

\author{
Stephanie Wilde* \\ SKOPE (Skills, Knowledge and Organisational Performance) \\ Oxford University Department of Education \\ 15 Norham Gardens \\ Oxford \\ OX2 6PY \\ E-mail: stephanie.wilde@education.ox.ac.uk

\section{Susan James Relly} \\ SKOPE (Skills, Knowledge and Organisational Performance) \\ Oxford University Department of Education \\ 15 Norham Gardens \\ Oxford \\ OX2 6PY \\ E-mail: susan.jamesrelly@education.ox.ac.uk \\ * Corresponding author
}

\begin{abstract}
This article focuses on the role of training managers (TMs) in UK participation in WorldSkills Competitions (WSC). The TM role is outlined, according to the perceptions of the TMs, and there is analysis of the benefits to them of participation, as well as the barriers they face, and the benefits and barriers available to participating further education colleges and employers. The article is based on analysis of semi-structured interviews with almost the full cohort of UK TMs preparing competitors for WorldSkills Brazil 2015, and concludes with reflections on the vision and purposes of UK WorldSkills participation.
\end{abstract}

Keywords: worldskills, training managers, qualitative research, skills competitions, vocational training and education

\section{Bibliographical notes:}

Dr Stephanie Wilde is a research officer at the Department of Education at the University of Oxford, UK. Her research interests focus on WorldSkills and research on transitions.

Dr Susan James Relly is an assistant professor at the Department of Education at the University of Oxford, UK. Her research interests focus on WorldSkills, vocational education and training, and apprenticeship. 


\section{Introduction}

The WorldSkills Competition (WSC) is the largest vocational education and skills excellence event in the world. The competitors are selected from skills competitions in WorldSkills member countries. WorldSkills competitions take place every two years with competitors aged between 18 and 22. The UK fields competitors in around 40 different skill areas (see James and Holmes, 2012), and the UK has competed in the competition since 1953. Prior to applying to compete in WSC, the competitors may be full-time college students, apprentices, university students, in employment or running their own businesses. The final team competes against other countries, with the 2015 competition being held in São Paolo, Brazil.

A large number of people are involved in this endeavour, including the competitors and the training managers, as they are titled in the UK. There is a TM for each of the skills in which the UK competes. As the title implies, they are responsible for training the young people in preparation for the WSC, as well as fulfilling other roles in terms of supporting and guiding the young people and carrying out administrative duties. This paper contextualises and critically examines the role of the WorldSkills training managers (TM) in the UK.

The article is based on the analysis of semi-structured interviews with almost the full cohort of TMs engaged in preparing competitors for the WorldSkills Competition (WSC) 2015 in São Paolo, Brazil. The study is exploratory in nature, and is based on empirical data collected with the TMs. As such, the aim of the research was not to generate theory or to work within a particular theoretical framework.

As the title of this article indicates, it also addresses the question of winning medals as the primary aim at WSC, and particularly gold medals. Perhaps there has been too strong a focus generally on performance and winning, with insufficient focus on raising aspirations and standards in vocational education and training (VET) in the UK in a broader sense. The article argues that, despite the arguably relatively poor effectiveness of VET in the UK, some TMs and competitors seem to have a 'Midas touch' which means they win (gold) medals when competing against the best in the world although many of whom have trained and studied within better functioning VET systems than the UK.

At the same time, the article argues that there may be an element of 'fool's gold' at work for TMs and competitors from the UK in WSC, since the allure and lustre of achieving at WSC may remain well beyond the reach of many UK learners. In addition, there is a question regarding the cost of and investment in WSC, and the extent and depth of its reach for most learners in a climate of reduced financial capacity for further education (FE) colleges and businesses. This issue of investment and cost was not a research question in this study, but emerged in a number of interviews with TMs. Arguably, the effort put into the WorldSkills endeavour can only be justified if it benefits a wider group than just the participants.

\section{Background}

The research reported here forms part of the Developing and understanding Vocational Excellence (DuVE) suite of research projects, which focus on WorldSkills. ${ }^{1}$ The underlying premise of the DuVE project is that developing vocational excellence, as exemplified by the WorldSkills initiative, can potentially raise standards and aspirations in the wider system. Currently, the VET system in the UK is facing

\footnotetext{
${ }^{1}$ The project website is at: http://vocationalexcellence.education.ox.ac.uk/
} 
many difficulties, including: lack of parity of esteem with academic education (Pring, 1995); insufficient funding (Keep, 2014); a lower level of engagement from employers than would be ideal (Keep, forthcoming) and entrenched inequality (Keep and Mayhew, 2014); and an economy with a dwindling manufacturing base. This article focuses on understanding the role TMs can potentially play in aiming for and achieving that excellence within the context of WorldSkills.

\section{$3 \quad$ Research Questions}

There has been little systematic research on the role of the TMs in preparing UK competitors for WSC (Mayhew et al., 2013). Since the TMs play a central role in the training of the young people in Squad and Team UK this absence of research is perhaps surprising. HOST Policy Research (Rowe, Windmill, Willis and Opie, 2013) produced a report which focused particularly on benefits to TMs, but did not present the wider issues of the barriers and hindrances to effective performance by TMs. This study aims to contribute to filling this research gap.

The research reported here examines four main questions, which address both the benefits from and the barriers to WorldSkills participation by TMs. These questions are:

1. What are the key elements of the TM role, as perceived by the TMs?

2. What are the main benefits of participation in WorldSkills UK for TMs?

3. What are the main barriers and difficulties faced by TMs?

4. What are the benefits from and barriers to participation for colleges and employers, as perceived by the TMs?

These questions emerged from previous research by Mayhew et al., (2013). The questions focused on the TMs and competitors, but also on the broader context of their work, including further education (FE) colleges and employers.

\section{$4 \quad$ Methodology}

The findings presented here emerged from semi-structured interviews with 36 of 38 UK TMs in post for the two-year training cycle preparing competitors for WorldSkills 2015 in São Paolo, Brazil. Two other TMs could not be interviewed for practical reasons. The findings reported here therefore represent nearly all skills in the areas of construction, hospitality, engineering, creative, building services and automotive, amongst others, of the TMs engaged for WSC 2015 (see $\mathrm{http} / / /$ worldskillsuk.org/squad-team/home for a full list of the skill areas).

In terms of the characteristics of the TMs, 30 out of 36 were male, and all the TMs interviewed were white British/Irish. Their employment contexts were as follows: 13 were full-time lecturers in FE colleges, nine were self-employed, nine were retired, and five were industry-employed. This indicates that only roughly one third of TMs were lecturing full-time in FE, which was a surprising finding, as the expectation had been that the majority of TMs worked in FE. The TM role is supported, to a large extent, by a cohort of retired and self-employed workers.

In terms of their length of service as TMs, the table below indicates when each of the TMs currently in post started work as a TM. This shows that a majority of TMs had experience prior to the current WSC cycle. 
Table 1: Year started TM role

\begin{tabular}{|l|l|l|l|l|l|l|l|l|l|l|l|l|}
\hline $\begin{array}{l}\text { Pre- } \\
2000\end{array}$ & 2002 & 2003 & 2004 & 2005 & 2006 & 2008 & 2009 & 2010 & 2011 & 2012 & 2013 & 2014 \\
\hline 3 & 1 & 1 & 1 & 3 & 3 & 2 & 3 & 4 & 5 & 5 & 2 & 3 \\
\hline
\end{tabular}

The interviews took place between March 2014 and December 2014 and were designed to elicit TMs' views in relation to each of the four main research questions. All of the interviewees were guaranteed full anonymity and therefore the reported data do not include skill area or geographical location.

All the interviews were recorded and transcribed. In the first stage of analysis, the overarching themes, as well as sub-themes, were identified within each research question. These followed, to some extent, the interview schedule developed for the study which focussed on the following main areas: narratives of how the TMs became involved in WSC; modes of training the competitors; benefits of carrying out the TM role and barriers to carrying out the role. In the next stage, crossinterview analysis and comparison was carried out to establish the key themes and identify salient quotations for the main arguments.

Sections 4 and 5 examine the perceived roles and main benefits of and barriers to TMs' participation in WorldSkills UK, while Section 6 looks at benefits and barriers to FE colleges and employers from the TMs' perspective.

\section{The Findings}

\subsection{The Training Manager Role}

The TM role is complex and challenging. Training the competitors is, of course, the main focus, as well as attending competitions. In addition, TMs perform a range of organisational and administrative tasks, liaise with colleges and employers on behalf of competitors, participate in the technical conferences run by Find a Future (the organisation responsible for preparing UK competitors for WSC) as preparation for participation in competitions, and organise external training and specialist equipment for their competitors.

The role is unremunerated, although TMs may apply for a daily rate of $£ 150$ in certain circumstances and expenses are reimbursed. These circumstances apply when TMs are self-employed, and therefore potentially forfeiting income on the days when they work for WSUK, or if TMs are retired. In the case of TMs who work as lecturers in FE, the eligibility for the $£ 150$ daily rate transfers to the college, and the costs of replacement teaching can be claimed up to that value. For those who work in industry, their employer can claim this daily rate as compensation for their absence from their work that day. A small number of TMs, colleges and employers chose not to claim this daily rate, seeing their contribution as a way to 'give back' to society.

The recruitment and selection of TMs is run by Find a Future. Each TM is appointed for one WSC cycle, and must re-apply if they wish to continue in the role for a further competition cycle. Advertisements are placed in the FE professional publications and in the relevant trade journals. Interviews are held to finalise appointments.

The TMs interviewed used a range of training approaches, including individualised training and flexible modes of delivery, feedback and support. Training was delivered by TMs themselves, by invited experts and sometimes by WorldSkills alumni (former competitors). A large number of TMs mentioned the need to tailor 
the training to the individuals participating in the WorldSkills 'journey', as young people enter the WorldSkills process with varying types and standards of skill sets, approaches to learning and personal characteristics. All TMs described the potential contribution of 'one-to-one' training:

The thing that came back from when we did the evaluation last time with the competitors was that they would have liked more one to one training rather than group training. Because they're all competing against each other, they didn't all feel as though they wanted to ask all the questions, because they didn't want somebody else to know and give away tips and tricks. They all learnt in different ways and they all needed help in different areas.

In addition, there is a need to guide the competitors through the specific challenges of WSC (most importantly, the timed element of the competition, because competitors are challenged to complete projects to strict deadlines, and also the noise levels at the competition, for example). This quote from a TM shows the effect of the time pressure:

I've noticed that a lot of people fall apart under pressure, when it comes to making stuff quickly. Some of them are in workshops where they get all the time in the world to make something, quality is good, but it's not so relevant to World Skills, so it's really two approaches to it - one is technique-based, working on their skills, and some people that's taking them back to basics, in other competitors it's refining what's already there - and then also how they approach working to a time-specific task.

Almost all TMs worked with tasks set at previous competitions as 'test projects' to guide the training for their competitors.

This range of tasks and responsibilities indicates the complexity of the TM role, and the need for the TMs who are recruited into this role to be suitably qualified and experienced in their skill area.

\subsection{The main benefits of participation in WorldSkills UK for TMs}

All the TMs interviewed were very quick to identify a range of benefits to them of carrying out the role, and clearly relished the challenges of the post. For example, they all referred to the benefit to them of the community of peer TMs in the UK, but also internationally:

The benefit is working in a bigger team, getting to meet loads of different people, getting to make new friends around the world. It's a very small world when it comes to the actual skill. Training in different countries - we've trained in Germany and Switzerland - seeing the way they're teaching in their colleges has been a big bonus.

This community includes all of the UK TMs and extends to include the young people involved in various ways, the colleges and employers contributing to the shared enterprise, as well as national and international partners. They also mentioned learning from other UK TMs from other skill areas: 
I feel my benefits are, it widened my knowledge skills. I'm working with the other Training Managers, you know, that has been fantastic, because I understand the intricacies of their skills as well. I use the analogy of a WorldSkills family, but you do, you make friends, you make acquaintances around the globe; the fellow training managers, we are extremely close.

As the quotes above indicate, the community of TMs supports them in developing greater understanding of developing teaching approaches, and also in building personal and professional contacts in their skill area. In addition, the TMs described a sense of a common aim, namely the pursuit of vocational excellence:

I like the thought of mixing with other professionals who have the same thoughts, internationally and nationally, because there's definitely a swell of goodwill there, that we're all after one thing - that is promoting excellence.

Many of the TMs also identified professional benefits to the role, such as maintaining and developing high-level skills and knowledge in their area:

For me it's keeping on top of my skills area, skills sets, keeping current, staying current.

Personal benefits mentioned by TMs in the study became clear through their use of language as they described the benefits of participating, using vocabulary such as 'buzz', 'addictive', 'addiction' and 'adrenaline':

To see youngsters go through this process is a massive buzz. For anybody that's involved, I'd be very surprised if they don't get an adrenaline rush to see these youngsters doing well and when you see ceremonies and people getting medals, it's fantastic.

Many of the TMs also described the pride they felt at representing their country as a personal benefit, and a motivating factor in their work. The Team UK uniform held a deep symbolic meaning for them, and some TMs described their sense of pride at wearing it:

I'm never going to be a David Beckham, you know, I'm not going to play for England at football or cricket or anything like that, but I actually feel very honoured and very proud when I'm representing the country.

With regard to the language chosen by the TMs during the interviews, the term 'journey' came up frequently to describe the competitors' progress through the preparation for the competition and, for some, participation in WSC. For almost all the TMs in the study, the competitor was at the heart of the work they did:

The benefit for me is to see the competitor get the outcome at the end, that's the ultimate, that's the payback for me.

The TMs described their sense of privilege to be working with 'the best in the country'. The reasons for this were that it meant that they had greater freedom with their training approaches than they might have had in their full-time jobs in FE or 
industry, because they were aware of the competitors' hunger to learn and, ultimately, to surpass their TMs in their skill levels. A further benefit for the TMs was that they had the opportunity to take any new knowledge or teaching practices back to their own working context:

I think the biggest benefits for me are what I'm able to bring back to my own teaching practices and share around here.

The benefits for the TMs can therefore be summarised as networking benefits (with peer group UK TMs, international contacts, competitors and alumni), genuine enjoyment of the training process and competition, and maintaining and enhancing their skills and knowledge. The TMs belong to a community and contribute to the enterprise of promoting, creating and sustaining excellence in their respective skill areas. Despite the diversity in their skills, mutual support and enhancement is possible through the overlap in their engagement with competitors, for example, and their choice of approaches to learning. The WSC provides the TMs with a shared discourse, and also a shared time-table across the competition cycle. They are all working towards the shared aim of vocational excellence.

\subsection{The main barriers and difficulties faced by TMs}

Understanding the barriers and difficulties faced by the TMs is important in order to improve the recruitment and training of TMs in the UK. These barriers may also compromise the commitment, performance and effectiveness of TMs already in post.

The key difficulty mentioned by all TMs was the intensity of the time commitment, and for those who are employed, the pressures involved in having fulltime jobs alongside the TM role:

It's the time commitment that's the number one issue, trying to find that time around the day job which is also a full-time job.

Officially the time commitment is 90 days across the two-year cycle, including around 20 days for the WSC in Brazil in August 2015, as well as four days at the Skills Show in Birmingham.

TMs who were FE lecturers (just over one third of the 36 interviewed) noted difficulties regarding the time spent away from college, such as the need for replacement teaching and the need to make up work accumulated during the time spent away. For some TMs who were in industry, there were potential problems with requesting time away from work, particularly at short notice, but other TMs also commented on the high level of support from their employers. For selfemployed TMs, full days spent on WorldSkills work could mean forfeiting orders and income. Of course, the retired TMs did not face these same issues, and had greater flexibility in their schedules.

The second major difficulty identified by the TMs was dissatisfaction with the financial arrangements, and particularly the delays in the reimbursement of expenses:

I mean it is meant to be a voluntary role, which the majority of it is. But it costs me money and my major problem is that we don't always get paid our expenses very quickly. 
The third issue that emerged from many of the interviews was a lack of structure in the handover of the TM role, in terms of the preparation offered for the role:

I'm surprised that for new training managers they don't have, like, an induction programme.

For TMs who had not been in the role for a long time, this meant that they recalled dealing with all the requirements of the TM role as extremely challenging. One recently appointed TM described this as 'flying in the dark'. Perhaps because of their own experience, many of the TMs interviewed were already considering specific plans and courses of action for arranging for their successors:

I'd like to hand it over properly, to show them the nuts and bolts of the job, this is how you go through the processes, but sort of more so with the training, it's developing the training plans.

The fourth difficult issue to emerge was the fact that the TMs did not perceive their work to be receiving a high level of recognition. For example, the official acknowledgement of their work is rather limited - perhaps a formal letter of thanks after the WSC. Some TMs pointed out that their own personal and professional support networks play a major role in their work, and wondered whether more could be done to include them in a small number of events during the cycle, for example at the Skills Show.'

The TMs indicated that these barriers and difficulties could potentially compromise the effectiveness of their work, their professional identity and their willingness to extend their commitment for additional cycles. These arguments also applied to future TMs, and the incentives they might seek in order to take on the role. On the other hand, it was clear during the interviews that the benefits of the role, for almost all TMs, outweighed the difficulties.

\subsection{TMs' perceptions of the benefits from and barriers to participation for colleges and employers}

The WorldSkills UK endeavour relies on the input of various groups: the TMs, the young people participating in the competitions, their support networks, the organising input of Find a Future, and also the significant role played by further education (FE) colleges and employers.

FE and employers contribute to the WorldSkills UK endeavour in a number of ways, including: releasing staff and students to train for and participate in WSC; providing training venues for competitors and TMs; and offering equipment to use in training.

In terms of the benefits for FE colleges and employers, they include: public relations benefits; networking opportunities and enhanced skills knowledge. With regard to the former, FE colleges and employers may include details of WSC participation by TMs and students in company brochures and college prospectuses. As for networking, WSC participation provides opportunities for TMs to network locally, regionally, nationally and internationally, with experts in the same or similar field, other trainers and competitors and with manufacturers and industry partners. In terms of enhanced skills knowledge, the TMs interviewed who worked full-time as FE lecturers commented that the wider college community benefited through 
knowledge exchange with colleagues and also enriched learning opportunities for students:

That filters through to others because I'm leading other lecturers, so the other lecturers are getting the benefit of the training that I receive because I glean a lot from WorldSkills in the further training that I give the competitors.

TMs working at colleges also pointed out that their knowledge of WSC and embeddedness in the WorldSkills organisation encouraged participation in WorldSkills, which may then raise the profile of the college and the course:

It benefits this college particularly, maybe it's by chance or because I'm the lecturer here, in that we have had WorldSkills competitor after WorldSkills competitor and for the last four cycles, there's been somebody from this college involved.

One area the TMs identified for improvement was the media and public relations work for WorldSkills UK as, in their view, FE staff were not optimally informed about the potential benefits of competition involvement in general:

I think the key is to get more colleges involved. There seems to be almost like a 'premier league' of colleges that know about WorldSkills, and all of our competitors [for a particular skill area] come from those three or four colleges. None of the other colleges really know about it.

Many TMs also pointed out the challenges associated with changes in the UK organisation for WSC participation. This can make it difficult to communicate to employers what WorldSkills is, who is involved and how the organisation is structured. One TM described a conversation with an employer, to persuade them to get involved:

I was, like, 'what are we called now?' So that was Skill Funding Agency and that one is WorldSkills UK and that one is Find a Future. I just kind of said, 'look at the end of the day we can't do it without the employers'.

In summary, the two main factors mentioned by TMs as barrier to participation by colleges and employers were: the time commitment and time away from their primary workplace.

\section{$6 \quad$ Midas Touch or Fool's Gold?}

The aims of WorldSkills, according to the WorldSkills website are to:

- 'Expose youth to a variety of skilled careers and equip them with the tools and resources they need to build a future.

- Communicate the benefits of holding a WorldSkills event to Members.

- Organize skill competitions and events for young people on all levels all over the world.

- Be a place and a platform for celebrating world-class excellence in skills by showcasing the next generation of skills talent. 
- Explain the motivational and educational benefit of competitions by showing how they build Competitors' character, confidence, commitment, and self-esteem.

- Offer companies, industries, and trades a chance to meet and recruit skilled people who have demonstrated that they are at the "top of their game.' (worldskills.org)

There is a tension between these wider goals and the narrower interest in the medals table and improving results between competitions. UK media reports on WorldSkills show that there is intense interest in winning medals, especially gold medals, as well as bronze and silver medals and medallions of excellence.

\subsection{The Midas touch?}

For the TMs in this study, the motivation for competitors to do well, perform at the WorldSkills standard and possibly win a medal was strongly present in their discussion of their role:

Well we went from nowhere to a gold medal, that's quite a good thing. We have proved that the UK is up to international standards, and I'm quite proud of that.

When asked about their key contribution, a TM who had been carrying out the role for some years charted their work through the medals:

I suppose training a gold medallist! I've trained one gold medallist. London 2011. All the time I've been involved as a training manager from 2005, my competitors have always achieved medallion of excellence or better which is quite a challenge in itself, to say you've trained the people to be world class. In 1995, the lad I was training won a bronze medal so a bronze and a gold, that's not so bad.

Many TMs commented that they perceived the starting level of their competitors in some skill areas to be significantly lower than the starting levels of competitors in some other countries, leaving them more to do in the two-year cycle to prepare competitors. In the technical skill areas, they often referred to basic mathematics and measuring skills, for example.

As such, the 'Midas touch' argument could be applied to the TMs and their competitors representing the UK, who go forward to win gold at WSC, in that they are doing so through the intense effort, commitment and teaching and learning talents of the TMs and their competitors. In line with the sport analogy, there is an inherent problem with this, since there will always be individuals of great talent, while the broader aims of sport are to ensure that all people engage in a good amount of exercise, in line with their abilities and wishes; and the broader aims of any VET system are to promote high quality teaching and learning, with good routes into employment, for students of all abilities and in all learning environments. The key question here is: does WorldSkills participation achieve this? The current study was not designed to answer this question, but it is one of those that emerged for future research. 


\subsection{Fool's gold?}

There is a significant tension between the concept of so-called elite skills competitions, and the concept of raising standards and skill levels across the board. Can WorldSkills, and skills competitions in general, do this? This topic formed part of the interview discussion with some TMs. If so, how can the work of WSUK be supported to enhance this double contribution? If not, does that mean that the WSC become a kind of 'fool's gold', promising access to internationally acclaimed standards of skills, which remains a false promise to the majority of trainers and learners?

For the UK TMs specifically, the issue of the skill levels of competitors in Squad and Team is crucial, because it affects the level of the training they are able to offer. The competitors are the 'best in the country', and yet the TMs repeatedly commented on the fact that, before they could begin WSC-oriented training, in some cases additional support with basic skills was required for some young people.

An additional element of the 'fool's gold' concept is that the lustre of WorldSkills does not seem to be shared out amongst FE colleges in the UK. Rather, particular colleges are dominant:

Once you get inside that circle of people that participate in competitions, and it's true today, I can name you the colleges that will participate and get people through to the national final year on year because it's the same ones all the time. You can virtually name the colleges that will end up in the final every time.

This situation undermines the potential 'Midas touch' effect of WSC, since other colleges and geographical areas will find it concomitantly more difficult to access the opportunities and the kudos of WorldSkills. It follows from this that those colleges which are heavily involved, perhaps by having a TM on the staff, receive disproportionately high benefits from their involvement.

An additional element of the 'fool's gold' argument is that UK WorldSkills participation cannot only be about gold medals, in the same way that the UK higher education system is not only about Oxbridge Firsts. Rather, the journey undertaken by each and every young person, whether in early heats, or in Squad or if selected to be the UK Team member for their skill, is valuable in its own right. Indeed, the TMs interviewed used the term 'journey' frequently to describe the extraordinary progress made by many of the competitors:

I mean, we've seen growth from a few competitors - just because they don't make the team, if they make the squad, I think their journey turns into a really positive one, and you'll see the growth.

\subsection{The WorldSkills 'vision'}

How does UK WorldSkills participation fit with the 'vision' put forward by WorldSkills International? The WorldSkills website describes its vision in the following terms:

'WorldSkills is the global hub for skills excellence and development. Through international cooperation and development between industry, government, or- 
ganizations, and institutions, we promote the benefits of and need for skilled professionals through grass-roots community projects, skill competitions, and knowledge exchange. We show how important skills education and training is for youth, industries and society by challenging young professionals around the world to become the best in the skill of their choice.

WorldSkills is the collective voice for skills excellence and development in vocational, technological and service oriented careers around the globe. Since 1950 we have raised the awareness among youth, as well as their parents, teachers and employers, that our future depends on an effective skills training system. Today WorldSkills represents more than 45 skills in 72 Member countries and regions, all working together with youth, educators and industries to help prepare the workforce and talent of today for the jobs of the future.' (https://www.worldskills.org/about/worldskills/)

The research with TMs indicated that many of the features of this vision are being reflected in the work of WSUK, particularly: international cooperation and development; challenging young people to become the best in the skill of their choice, and knowledge exchange. However, our research has shown one key area for improvement in WorldSkills participation in the UK in the vision outlined above, namely: the vision of raising awareness '....among youth, as well as their parents, teachers and employers, that our future depends on an effective skills training system'.

It can be argued that the list of target groups might also include policy makers and the wider media. The former, of course, have responsibility for ensuring that the UK has an 'effective skills training system', which observers argue is currently not the case. The latter could bring the work and vision of WorldSkills to a wider audience, beyond those already 'in the know' or in contact with competitors and TMs. However, as yet this has not been the case. Even when WorldSkills was held in London (2011), the media coverage was less then extensive. As one TM phrased it:

Certainly in the UK the WorldSkills PR and media isn't fantastic. Unless you know somebody who's in there, you never get to hear of it.

The TMs in the research also indicated their perceived lack of recognition of the work they do:

I wouldn't be able to name you what sort of recognition we do get. I think if I was doing it just for that, then I would have walked away a long, long time ago, because I don't feel that there is really a huge amount of official recognition. But again I guess what sort of recognition is there that you could get for doing it? We get a certificate at the end of it that says "you participated" and that's it.

For UK participation in WorldSkills to achieve maximum impact, the level of recognition of this endeavour and the limited media coverage must both improve. 


\section{Concluding remarks}

This exploratory research undertaken with TMs has shown that their embeddedness in a strong community with their TM peers, UK competitors and international contacts, contributes significantly to their effectiveness in the role and their enjoyment of it. However, the wider contexts of Find a Future, further education colleges and employers are not as strong, and therefore will need further development and support to provide an optimal context for the work of TMs in the future. To do this, further investigation about international practices for preparing for WSC could be useful.

Returning to the title, it seems that both elements apply in certain ways to the work of the TMs. The UK VET system is facing serious difficulty, and vocational skills continue to suffer from a lack of parity of esteem with academic qualifications. Despite this, TMs from the UK and their competitors are winning medals at WSC and competing at the international standards required. As such, both the TMs and the competitors can be argued to have a 'Midas Touch'.

The element of 'fool's gold' is less positive, of course. The lustre and success of UK participation in WSC must not be used to disguise some of the serious problems in the UK VET system. These include: funding uncertainties; difficulties in recruiting and retaining gifted lecturers; the struggle to maintain credible progression pathways for young people and the need for greater employer participation. In the context of the current and future funding crisis, it will be imperative that the WSUK initiative finds a broader reach than a small group of regularly participating colleges and employers, and becomes relevant to the raising of aspirations of all learners, regardless of skill type and skill level. The TMs are central to this work, and official and appropriate recognition of their contribution is essential. In this way, the pursuit of vocational excellence could become part of the journey of all learners in VET in the UK, and not just the 'chosen few' who go on to represent the UK at WSC.

\section{References}

James, S. \& Holmes, C. (2012). Developing Vocational Excellence: Learning environments within work environments. SKOPE Research Paper No. 112 SKOPE: University of Oxford.

Keep, E. (forthcoming). Exploring Employer Ownership. CIPD (Chartered Institute of Personnel and Development).

Keep, E. (2014). What does skills policy look like now the money has run out? Association of Colleges. Available at:

http://www.aoc.co.uk/sites/default/files/What_Does_Skills_Policy_Look_Lik e_Now_the_Money_Has_R-un_Out_0.pdf.

Keep, E. \& Mayhew, K. (2014). Inequality - 'wicked problems', labour market outcomes and the search for silver bullets, Oxford Review of Education, 764781.

Mayhew, K., James, S., Chankseliani, M. \& Laczik, A. (2013). Benefits of Developing Vocational Excellence: A Report to the National Apprenticeship Service of Project 3 of the DuVE suite of projects. Available at: http://vocationalexcellence.education.ox.ac.uk/wordpress/wpcontent/uploads/2014/02/DUVE-Project-3-Final-Report-Phase-1.pdf.

Pring, R. A. (1995). Closing the gap. Liberal education and vocational preparation. London: Hodder \& Stoughton. 
Rowe, V., Windmill, B., Willis, D. \& Opie, M. (2013). Identifying positive stimuli for increasing applications to the role of UK Training Manager and expert for WorldSkills competitions. Available from:

http://www.hostpolicyresearch.com/ Accessed 19 June 2015. 